\title{
Value Creation for Emergency Supply Chain Members: An Abstract
}

\author{
Iana Shaheen (Lukina) and Robert Hooker
}

\begin{abstract}
In disaster management, a response to an incident that affects various people, communities, and organizations involves multiple parts of the supply chain. When a disaster occurs, people from the entire emergency supply chain are pulled together into one response team in order to ensure an effective disaster response. The whole team needs to work jointly as one unit, because even a small mistake can pose a serious threat to disaster victims' and team members' safety, health, and well-being.

Research shows that individuals involved in emergency response teams suffer from stress, depression, and anxiety (Tomazin, 2013). Further, the disaster can affect their lives and threaten their well-being (Thompson \& McKenna, 2012). In such harsh and unstable working conditions, motivating team members is one of the most critical factors for ensuring a disaster response's success (Pettit \& Beresford, 2009). Supply chain leaders need to develop an environment where team members are able to create value that will improve their morale and dedication. The current research is attempting to answer the question: how do supply chain leaders create value for the disaster team members?
\end{abstract}

References Available Upon Request

I. Shaheen (Lukina) $(\bowtie) \bullet$ R. Hooker

University of South Florida, Tampa, FL, USA

e-mail: ianalukina@usf.edu; rhooker@usf.edu 